This item was submitted to Loughborough's Research Repository by the author.

Items in Figshare are protected by copyright, with all rights reserved, unless otherwise indicated.

\title{
Comment on: Subjective thermal strain impairs endurance performance in a temperate environment
}

PLEASE CITE THE PUBLISHED VERSION

https://doi.org/10.1016/j.physbeh.2019.03.006

PUBLISHER

(C) Elsevier

VERSION

AM (Accepted Manuscript)

\section{PUBLISHER STATEMENT}

This paper was accepted for publication in the journal Physiology \& Behavior and the definitive published version is available at https://doi.org/10.1016/j.physbeh.2019.03.006.

\section{LICENCE}

CC BY-NC-ND 4.0

\section{REPOSITORY RECORD}

Lloyd, Alexander, and George Havenith. 2019. "Comment On: Subjective Thermal Strain Impairs Endurance Performance in a Temperate Environment". figshare. https://hdl.handle.net/2134/37253. 


\section{Accepted Manuscript}

Comment on: Subjective thermal strain impairs endurance performance in a temperate environment

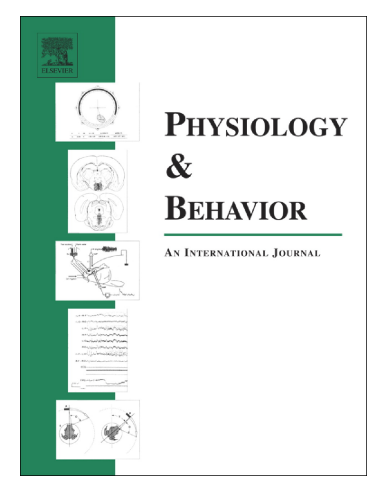

Alex Lloyd, George Havenith

PII: $\quad$ S0031-9384(19)30148-9

DOI: $\quad$ https://doi.org/10.1016/j.physbeh.2019.03.006

Reference: $\quad$ PHB 12487

To appear in: $\quad$ Physiology \& Behavior

Received date: $\quad 7$ February 2019

Revised date: $\quad 8$ March 2019

Please cite this article as: A. Lloyd and G. Havenith, Comment on: Subjective thermal strain impairs endurance performance in a temperate environment, Physiology \& Behavior, https://doi.org/10.1016/j.physbeh.2019.03.006

This is a PDF file of an unedited manuscript that has been accepted for publication. As a service to our customers we are providing this early version of the manuscript. The manuscript will undergo copyediting, typesetting, and review of the resulting proof before it is published in its final form. Please note that during the production process errors may be discovered which could affect the content, and all legal disclaimers that apply to the journal pertain. 
Comment on: Subjective thermal strain impairs endurance performance in a temperate environment.

Alex Lloyd $\mathrm{PhD}$, George Havenith $\mathrm{PhD}$.

Environmental Ergonomics Research Centre, Loughborough Design School, Loughborough University, Loughborough, United Kingdom.

*Corresponding Author: Alex Lloyd PhD. a.lloyd@lboro.ac.uk

Dear Editor,

We read with interest the recent publication by Van-Cutsem et al. (2019) in this journal on the impact of subjective thermal strain on endurance performance. Thermal discomfort is widely thought to have a critical role in modulating performance in the heat (Cheung, 2010; Nybo et al., 2014; Flouris \& Schlader, 2015); however, the relative effects of physiological and subjective factors to heat-induced performance decrements are difficult to isolate experimentally. From the presented findings, the authors conclude that the subjective experience of thermal strain, independently of change in 'general' physiology (i.e. cardiorespiratory, metabolic and thermoregulatory state), modulates endurance performance in the heat. We write to express our concerns with this interpretation, given the methodology followed.

The study by Van-Cutsem et al. (2019) sought to induce subjective thermal strain as an independent (of body thermal and general physiological state) mediator of performance, using $40^{\circ} \mathrm{C}$ conductive heating applied to a $1200 \mathrm{~cm}^{2}$ area on the upper back. However, as demonstrated by the calculations below, the application of a $0.12 \mathrm{~m}^{2}$ heat pad during exercise induces a significant change in the physical heat load to the exercising human. Below we detail a conservative estimate of the differences in 
heat load when exercising in the control and heat pad conditions of the present study. This contains the estimated heat gain from pad to skin, and the reduced dry and evaporative heat loss from skin to environment, caused by the heating pad (Havenith \& Fiala, 2016).

Dry Heat Gain from the pad to the body = $\left(\left(\mathrm{T}_{\mathrm{pad}}-\mathrm{T}_{\mathrm{sk}-\text { under pad }}\right) / \mathrm{R}_{\mathrm{ct}}\right) \times$ PSA

Reduced Dry Heat Loss from the skin to the environment due to pad coverage = $\left(\left(\mathrm{T}_{\text {sk-without pad }}-\mathrm{T}_{\text {air }}\right) /\left(\mathrm{R}_{\mathrm{ct}}+\mathrm{I}_{\mathrm{a}}\right)\right) \times$ PSA

Reduced Evaporative Heat Loss from the skin to the environment due to pad coverage $=$

$\left(\left(\mathrm{P}_{\text {sk-without pad }}-\mathrm{P}_{\text {air }}\right) /\left(\mathrm{R}_{\mathrm{et}}+\mathrm{R}_{\mathrm{ea}}\right)\right) \times$ PSA

Condition Difference $=$

$\uparrow$ Dry Heat Gain $+\downarrow$ Dry Heat Loss $+\downarrow$ Evaporative Heat Loss

(W)

Increase in Body Heat Content at Exhaustion due to the pad $=$

(Condition Difference x TTE) / 1000

Difference in Mean Body Temperature at Exhaustion =

$\uparrow$ Body Heat Content at Exhaustion / (Mass x Cp)

Percentage increase in total heat load $(\%)=$ 
Required increase in sweat evaporation to counteract pad effect $=$ (Condition Difference / $\lambda_{\text {eff }}$ ) 3600

Where: $T_{p a d}$ is the heating pad temperature; $T_{s k}$ is the local skin temperature (around $34^{\circ} \mathrm{C}$ without the heating pad); $R_{c t}$ is the thermal resistance of the $t$-shirt between the pad and the skin $\left(0.03 \mathrm{~m}^{2} .{ }^{\circ} \mathrm{C} . \mathrm{W}^{1}\right)$ affecting dry heat gain only; $\left(R_{c t}+I_{a}\right)$ is the sum of the T-shirt and air layer resistance affecting dry heat loss $\left(0.13 \mathrm{~m}^{2} .{ }^{\circ} \mathrm{C} . \mathrm{W}^{1}\right) ;\left(R_{e t}+R_{e a}\right)$ is the sum of the vapour resistance of the $t$-shirt and the air layer resistance affecting evaporative heat loss 10.016 $\left.m^{2} . k P a . W^{1}\right) ; T_{a i r}$ is the air temperature $\left(22^{\circ} \mathrm{C}\right) ; P_{\text {air }}$ is the vapor pressure of the air $(1.03$ $\mathrm{kPa}) ; P_{s k}$ is the vapour pressure at the wet skin's surface $(5.31 \mathrm{kPa})$; Metabolic rate is estimated based on $\mathrm{VO}_{2} \times 350$ (1225W); PSA is the pad surface area $\left(0.12 \mathrm{~m}^{2}\right)$; Mass is the participants mean body weight (69.8kg); $C p$ in the specific heat capacity of the human body $\left(3.48 \mathrm{~kJ} /\left(\mathrm{kg} .{ }^{\circ} \mathrm{C}\right) ;\right.$ TTE is the time to exhaustion in seconds in the heated pad trial (2092-s); and $\lambda_{\text {eff }}$ is the effective latent heat of evaporation of sweat $(2430 \mathrm{~J} / \mathrm{g}$ ).

Depending on the local skin temperature under the pad $\left(\mathrm{T}_{\text {sk-under pad; }}\right.$ estimated range: $34-39^{\circ} \mathrm{C}$ ), and the magnitude of increase in pad temperature during the trial (estimated range: $40-43^{\circ} \mathrm{C}$ ), this calculation indicates a $53-69 \mathrm{~W}$ increase in heat load in the heated pad condition, compared to the condition without the heating pad. If not compensated by thermoregulatory responses, the corresponding difference in heat storage and mean body temperature between conditions over the course of the trial would be $111-144 \mathrm{KJ}$ and $0.46-0.59^{\circ} \mathrm{C}$ respectively. Based on a metabolic rate of $1225 \mathrm{~W}$, this equates to a $4-6-\%$ increase in heat load. 
While no significant changes in core and mean skin temperature are observed by the authors, it is critical to recognise firstly that rectal temperature is slow to respond and relatively insensitive to non-uniform heating, and secondly that local skin temperature on the upper back in the heated pad area was not measured, and thus not considered in the calculation of mean skin temperature, which would have had a relevant impact on the skin temperature comparison. Furthermore, earlier work has indicated that a combination of core and skin temperatures do not necessarily reflect the actualchange in body heat content, irrespective of the weighting used (Jay et al., 2007). Lastly, based on the estimated increase in required sweat evaporation to compensate for the pad impact $(79-102 \mathrm{~g} / \mathrm{hr})$, it is highly probable that the increase in heat load was partially offset by the observed $19 \%(310 \mathrm{~g} / \mathrm{hr})$ increase in whole-body sweat rate, although despite the large size of the difference, this was not significantly different between conditions.

Thus, in our opinion, the physical calculations do not support the notion that 'general' physiological states are unaffected by the present intervention, which was the key assumption in Van Cutsem et al.'s (2019) interpretation. Rather, based on the current methodology used, either one, or a combination of: upper back skin temperature (and thereby when included in the calculation, true mean skin temperature), the wholebody heat content, whole body sweat rate, skin blood flow as well as thoracic spinal temperatures are different between conditions. Differences in any of these variables fundamentally prevent any clear separation between the impact of 'general' physiology (i.e. thermoregulatory, cardiovascular and metabolic state) and subjective experience on performance in the present study. Similarly, the issues highlighted 
above are also likely true of previous research using similar methods to manipulate heat balance (e.g. research utilising localised cooling methods).

On a separate note, we also feel it is pertinent to consider the authors' interpretation of the RPE interaction statistic and the disregard for the non-significant difference in RPE at each isotime in this interpretation. Two-way interactions statistics (condition $\mathrm{x}$ time) indicate whether the effect of condition is differential as time progresses; it is therefore plausible that a significant interaction statistic simply reflects the variable difference in RPE between conditions over time (e.g. the observed crossover in RPE between conditions over time). Importantly, interaction statistics should not be used to infer differences at the point when the participant took the decision to stop or continue exercise (i.e. $100 \%$ isotime). The isotime $100 \%$ comparison clearly shows that when participants were exhausted in the shortest trial (typically heat pad conditions), they were not experiencing a significantly higher RPE compared to the other trial (typically control). They were, however, experiencing different subjective and objective thermal states. We therefore urge caution in interpreting the present study as evidence in support of an RPE driven model of exercise performance, and argue that in fact, Van Cutsem et al. (2019) may present strong evidence to the contrary.

Finally, the counter-argument that sensory tolerance is not the cause of exercise cessation is of concern. The position taken by Van Cutsem et al. (2019) assumes that thermal discomfort and its effect on performance is based on the absolute subjective intensity of thermal discomfort, independent of the time exposed to that discomfort. Contrary to this notion, we postulate that tolerance to thermal, or any other form of discomfort, is temporally dependant e.g. exposure to a certain level of discomfort for 
5-hours is less tolerable than the same discomfort intensity for 5-seconds. Differences between subjective intensity and tolerance are widely recognised in pain and discomfort research (Schmidt et al., 2006; Streff et al., 2010; Geva \& Defrin, 2013), although their relative contribution to behavioural thermoregulation and exercise tolerance remains to be investigated.

In summary, based on the physical calculations of heat transfer, Van Cutsem et al.'s (2019) results should be interpreted as additional evidence for the role of already established physiological principles (e.g. Nybo et al., 2014), as well as perhaps thermo-afferent feedback and discomfort tolerance (e.g. Flouris \& Schlader, 2015), to heat-induced reductions in endurance performance.

References:

Cheung SS (2010). Interconnections between thermal perception and exercise capacity in the heat. Scand J Med Sci Sports 20 Suppl 3, 53-59.

Van Cutsem J, Roelands B, De Pauw K, Meeusen R \& Marcora S (2019). Subjective thermal strain impairs endurance performance in a temperate environment. Physiol Behav 202, 36-44.

Flouris AD \& Schlader ZJ (2015). Human behavioral thermoregulation during exercise in the heat. Scand J Med Sci Sports 25, 52-64.

Geva N \& Defrin R (2013). Enhanced pain modulation among triathletes: A possible explanation for their exceptional capabilities. Pain 154, 2317-2323.

Havenith G \& Fiala D (2016). Thermal indices and thermophysiological modeling for heat stress. Compr Physiol 6, 255-302.

Jay O, Reardon FD, Webb P, Ducharme MB, Ramsay T, Nettlefold L \& Kenny GP (2007). Estimating changes in mean body temperature for humans during 
exercise using core and skin temperatures is inaccurate even with a correction factor. J Appl Physiol 103, 443-451.

Nybo L, Rasmussen P \& Sawka MN (2014). Performance in the heat-physiological factors of importance for hyperthermia-induced fatigue. Compr Physiol 4, 657689.

Schmidt NB, Richey JA \& Fitzpatrick KK (2006). Discomfort intolerance:

Development of a construct and measure relevant to panic disorder. $J$ Anxiety Disord 20, 263-280.

Streff A, Kuehl LK, Michaux G \& Anton F (2010). Differential physiological effects during tonic painful hand immersion tests using hot and ice water. Eur J Pain 14, $266-272$. 